\title{
Virtual academic and the virtual librarian: real interdependency
}

\author{
S. Myburgh \\ School of Communication and Information Studies, University of South Australia, St Bernard's Road, MAGILL SA5072, Adelaide, Australia \\ sue.myburgh@unisa.edu.au
}

\begin{abstract}
This article is an exploratory study which observes some of the changes presently being experienced by academics, and identifies some of the issues which have yet to be resolved. It will be seen that these changes will demand a new type of relationship between academics, and academic and research (AR) librarians. Different responsibilities will be thrust upon AR librarians as their work becomes an increasingly vital complement to academic work - in particular controlling the scholarly electronic publishing done by academics at their institutions, protecting copyright and preserving intellectual property, assisting academics and students alike in gaining the necessary skills of information literacy; and in creating order out of the chaos that is the Internet, by locating useful and pertinent information in Cyberspace. Responsibilities for academic libraries will include providing the means for all students to have sufficient suitable access to Cyberspace.
\end{abstract}

\begin{abstract}
Hierdie artikel verken 'n aantal veranderinge wat tans deur akademici ervaar word en identifiseer sommiges waarvoor daar nog nie oplossings gevind is nie. Dit is duidelik dat hierdie veranderinge 'n nuwe verhouding tussen akademici en hul inligtingsbibliotekarisse vereis. Namate laasgenoemde se bydrae 'n noodsaaklike bestanddeel van akademiese werk word, sal nuwe verantwoordelikhede aan die bibliotekaris toegesê word. Verantwoordelikhede oor die beheer van vakkundige elektroniese publikasies van akademici, die beskerming van kopiereg en die intellektuele inhoud word hierby ingesluit. Ook die hulpverlening aan akademici en studente in die verkryging van die nodige inligtingvaardighede, die skepping van orde uit die chaos van die Internet deur die opspoor van nuttige inligting word die verantwoordelikheid van die inligtingbibliotekaris.
\end{abstract}

Universities are open organizational systems located in a turbulent environment known as the Information Age. They are embedded in a society lurching towards the end of the millennium, which presents a watershed and a precursor to yet more change. While the Information Age is shaped and informed by many factors, its outstanding characteristic is the ubiquitous use of Information Technology (IT). IT is a phrase used to describe the convergence between computing technology and telecommunications. IT is primarily concerned with the processing, storage and communication of information specifically in the form of digital data - without regard for the constraints of time or space. For many its epitome is the Internet.

The core activity of universities is the discovery and dissemination of information and knowledge, and their goal is to ensure that graduates are equipped with skills which will enable them to contribute to society and lead meaningful lives (Aulich, 1990). It comes as no surprise to discover that universities believe IT, in changing the way in which information is disseminated, will enhance their activities, and assist in the more efficient and effective achievement of their goals.

Some major issues that will change the work of the academic or research (AR) librarian and consequently the relationship between them, will be discussed. These include:

- changes in the objectives of education, so that graduates possess the skills required for lifelong learning;

- changes in the pattern of scholarly communication, and in particular electronic publishing; and

- necessity for increased access to the resources of Cyberspace, both physical and intellectual.

In the interests of accuracy, I prefer to use the term 'information worker' in this context, as the work of such staff will increasingly have to do with the broader issues of information management, particularly in electronic mode, than the association with 'books' that is suggested by the word 'librarian'. The work of an AR information professional is, indeed, affected by other different and discrete forces which cannot, however, be discussed here.

\section{Environment}

The turbulent environment in which universities operate includes many challenges in addition to those presented by IT. These I collectively call the Educational Crisis. It is a crisis, however, that is simultaneously partly created and partly solved by IT.

Aspects of the Educational Crisis are described as megatrends by Moseley (1995), who names less money, increased accountability, decreased access, new roles and responsibilities for faculty, increased use of technology, new revenue sources, increased competition and co-operation, and the question of whether there will be more centralization or decentralization. Necessary change is a point of view enunciated by Langenberg (1994), who notes that:

'The revolution in information technology requires that universities integrate information technology with their traditional missions of teaching, research and public service. To this end, universities must address ethical and legal issues and restructure themselves to better meet the needs of today's learners. In addition, new information technologies are creating new patterns in the research enterprise, with networks enhancing information sharing and data transmittal. Leadership and service are critical to strategies for tomorrow'. 
Change is a factor of modern life. We face change on a number of levels, and Sempsey (1994), in his literature review, comes to the conclusion that:

'It is generally speculated that computers and computer networks will transform (are transforming) the ways in which society functions. These changes are occurring on multiple levels, affecting our modes of production, our modes of learning, and even the ways in which we socialise. There is even evidence to suggest that use of interactive multimedia actually alters one's neurological configuration'.

Incorporating IT and restructuring the university is clearly not a simple task. It implies a reconsideration of the fundamental mission of the university. It demands a new formulation of what constitutes academic duties. In particular, it creates opportunities for new ways of communicating with peer groups, with students and with communities.

\section{Technological determinism}

Underlying the following description of some of the challenges facing universities lies a general imperative to engage with the Net and exploit its potential. On one hand, although it has been denied as a contemporary argument by some writers (Wacjman, 1991), there are undercurrents here of a school of thought known as technological determinism in the rush of universities to get online and exploit the facilities of the Net. Chandler (1995) states that '... technological determinism ... is still the most popular and influential theory of the relationship between technology and society'. In this line of argument, social and historical phenomena are explained in terms of one principal or determining factor. It is this factor that assumes determining characteristics, which simultaneously erode or destroy the element of choice. Technological determinism implies a suspension of ethical judgement or social control, and has an irresistible and irreversible quality. Chandler gives the following example of the use of deterministic language which commonly is used:

'The assumption of technological determinism can usually be easily spotted in frequent references to the "impact" of technological "revolutions" which "led to" or "brought about", "inevitable, far-reaching, effects or consequences". This sort of language gives such writing an animated, visionary, prophetic tone which many people find inspiring and convincing' (author's emphasis).

We become, at best, people who struggle to keep up with runaway technology, which we did not ask for, but without which we cannot survive. At worst, we become victims, and are left behind.

We must remember, however, that technology is in fact constructed by us: its reality is dependent upon the way we make it serve our own ends. We cannot refuse responsiblity for our use of IT.

\section{Changes in educational objectives}

One of the biggest issues facing universities is the placing of education, and modes of education, within modern society. What students need to know, and how they can best learn, are important issues in this context. It has become necessary to establish what tertiary education is for. The Aulich Report in Australia (1990) asked 'What is the purpose of higher education?' and reported on the qualities which graduates from Australia's higher education institutions should possess. This has subsequently been considered, modified and accepted by various Australian universities.

- 'They should be highly competent in the sciences and the arts underlying the practice of their professions;

- They should have sound understanding of the society in which they are going to practice - its history, cultural traditions, social structure and social mix;

- They should possess a capacity to look at problems from a number of different perspectives, to analyse, to gather evidence, to synthesize, and to be flexible, creative thinkers;

- They need to develop a capacity for lifelong learning to enable them to keep abreast of the world of rapid change in which they will practise; and

- They must be good communicators, orally and in writing. There are some key phrases in these statements: to have a sound understanding, to analyse, to gather evidence, to synthesize, to be flexible creative thinkers and good communicators. Each of these phrases implies that students need to be able to do more than access information - they need to be able to do something with that information. They need to develop wisdom and not just its appearance' (author's emphasis) (Aulich, 1990).

Notable among the characteristics of the model graduate is the need to engage in a process of lifelong learning and the importance of possessing the skills of information literacy which will facilitate this process. This is clearly important when we consider the well-documented and obvious explosion in the quantity of information available, that it is necessary to be able to distinguish the quality and usefulness of this information.

Goad (1995) reports that

'information literacy is essential to productive,

lifelong learning. It is the basic skill adults need to survive and ultimately succeed in education and the workplace ...'

He further defines an information literate person as one who:

- Recognizes the need for information.

- Recognizes that accurate and complete information is the basis for intelligent decision making.

- Formulates questions based on information needs.

- Identifies potential sources of information.

- Develops successful search strategies.

- Accesses sources of information including computerbased and other technologies.

- Evaluates information.

- Organizes information for practical application. 
- Integrates new information into the existing body of knowledge.

- Uses information in critical thinking and problem solving.

There is a distinct blurring here between the information processes of the AR information worker and the academic. The tasks that the academic, researcher, learner or information worker perform in their quest for knowledge are remarkably similar. There are, however, clearly two different sides to tertiary education. One is content-, competency-based, or curricular education, which achieves the acquisition of certain skills and knowledge of the principles of a certain discipline; the other is lifetime learning, and the acquisition of information literacy skills. The former can said to be the domain of the academic; the latter of the AR information worker.

Academics expect students to acquire and use the skills of information literacy. This will become an increasing challenge to AR information workers - they will have to teach not only these skills (much more intensively than the usual library tour permits) but in many instances they will have to train academics who, in many disciplines, cannot be described as expert library users themselves. One wonders how they are managing on the Net. Are they even aware that they could be retrieving more, pertinent information? Do they have the skills for dealing with information overload?

Institutionalized education is usually not sufficiently responsive to changes in the workforce and therefore is not able to prepare people for the demands that our rapidly changing world will make on them. This outlook is supported by Hardaway and Brewer (1995), who maintain that

'In an accelerating information-based economy, good jobs require analytical research skills, not simply the ability to read and write and follow instructions ... Many workers are becoming symbolic analysts. The exploding information base and intelligent tools of the modern economy make thinking skills far more important than the memorization of facts or rote exercises.'

This emphasizes the need for students not only to master the skills of information literacy to assist them with their studies, but also the need to continue to use these skills throughout their careers.

\section{Changes in scholarly communication}

Academics are involved with the transfer of information in the areas of teaching, research and community service. Academic life demands, inter alia, communication with peers nationally and internationally, teaching of local and remote students, collaboration on conference papers and grant applications, submission of papers to journals, identification of relevant literature, and collection of data. These functions are jointly referred to as the processes of scholarly communication. Academic work is therefore predicated upon information - the discovery, understanding, processing, communication and dissemination of information. As the Internet changes the patterns of information flows, and the traditional media of telephone and print are increasingly enhanced or replaced by widespread, fast, cheap and even interactive digital communication, it can be assumed that the processes of scholarly communication will change (Bass, 1995).

The traditional process of scholarly communication could be described as a kind of endless loop. Academics discover what is happening in their disciplines through keeping abreast of published literature - in both monographs and journals. In many areas, the time delay caused by the publication's cycle of monographs is too lengthy to represent the rapid developments in a field. Communication via journals, and presentations and inter-personal communication at conferences and seminars become increasingly common and necessary. Here academics can present their ideas and hear the ideas of others; be updated; engage in debate, and have their own conclusions challenged and refined. For example, prior to acceptance for publication, research is subject to a process of peer scrutiny by an editorial committee.

In due course, academics present their own material - at conferences, in published proceedings, in journals and in monographs - where it is in turn viewed by colleagues. However, keeping in touch with colleagues at conferences requires time and money - the latter commodity always being in short supply, in particular for junior researchers. (For women, the situation is often even more difficult because of their domestic duties.)

When published works become widely available (as indeed is the primary intention of scholarly communication), they are organized by the information sector. Some of the agents in this sector include large commercial abstracting and indexing services; researchers investigating, assessing the usefulness of information systems, compilers of indexing and coding languages and thesauri; compilers of literature reviews and bibliographies, the suppliers of access to online databases and the producers of CD-ROMs - and AR information workers.

The primary functions of the information sector are to identify what items are worthy of further dissemination; call in expert witnesses to verify that this is so; publish and distribute the material via suitable channels (including advertizing the availability of the work); select items from the universe of publicly available works to form cohesive and unified collections in certain areas, often in response to demands by user groups of such collections; and organize such collections through subject analysis and interpretation, indexing and coding, and the creation of descriptive metadata; organizing such metadata and providing access to it (in indexes, abstracts, catalogues and bibliographies). In so doing, the information sector strives to provide intellectual and physical access to the research materials.

The Internet is causing some changes in this scenario. Many of these processes are speeded up, avoided, or now exclude traditional information workers. For example, the use of teleconferencing and virtual conferences means that proceedings are seldom published, and even physical access is often difficult due to the exclusive nature of such communications. 
Regular attendance at conferences however becomes less compelling. It is far easier (and cheaper) to stay in touch with colleagues via email. The advantages of this for the academic are many: it is relatively cheap, it vastly expands the number of like-minded people with whom one can stay in contact; approaching known leaders in various fields is easier because of the informal nature of email; reaction times are far quicker - even interactive communication is possible; and the old system of invisible colleges becomes more inclusive, for academics and students alike.

An issue raised for the AR information worker is that important information may be disseminated in this mode which is not documented or archived. Although it can be rapidly relayed to its audience, the potential does not exist for an important message to be readily available after this first transmission, as it is not identified and stored.

More significantly, the Net provides the opportunity for academics to become their own publishers. This means bypassing peer review and scrutiny by avoiding editorial committees. There are several advantages of self-publication for the academic. Firstly, timelags between discovery of new findings and publication are greatly minimized. Secondly, what is maintenance of quality for some (via the referee process) means placing obstructions for others, making it difficult to get their work published. Another advantage is the possibility for constant modification as ideas mature or results are corrected.

For the AR information worker, this is a nightmare. It also means that publications have a good chance of not being described by the metadata services - they are not coded, indexed, abstracted, catalogued - which means that potential readers rely on the process of serendipity for discovery. Searchers can never be sure that they have located all relevant articles - and on the Internet this becomes even less likely. The challenge of finding ejournals, providing continuing access to them (in particular back copies), and identifying changing editions is an almost insurmountable one.

Such lack of bibliographic control has some more serious implications, however. It means that copyright and the protection of intellectual property become virtually obsolete concepts. Works can be plagiarized easily (in their entirety) off the Net, and the chances of this being discovered are low, as people struggle through a rapidly increasing volume of materials which are not organized in any consistent, cogent or centralized way.

However, out of this challenge, and with co-operation between the academic and the AR worker, the possibility exists to create a new model of publishing. It is common knowledge that journal subscriptions are extremely expensive, and providing access to journals - both intellectually and physically - has been a huge problem for academic libraries for decades. It is also known that while publishers charge substantial subscription rates for their participation in the process, the authors (as academics) do not receive recompense for their efforts. Indeed, universities financially support researchers, through their salaries and grants, to produce articles for publication in prestigious refereed journals. In most cases, the referees themselves do not receive payment for their contribution. Additionally, the university itself may not be able to afford subscription to the journal, so that authors will not always see their work in print!

The option that emerges out of this scenario is a desirable one. The university can employ a similar process - but provide some added benefits to both its authors and the readers. The scrutiny process could remain similar (so that questions about maintenance of quality could be avoided) but perhaps could involve a wider and more fluid community of referees (using the rapid and cheap email system). The articles themselves could then be described in terms of metadata before being posted onto a Web site. Access to them could therefore be easily facilitated. These articles could easily be permanently archived, as storage costs continue to drop dramatically. Ownership of the articles could therefore remain in the hands of the universities, who could not only protect copyright, but also construct a system whereby a modest charge could be made each time a copy of the article is requested - thus benefiting the author and the university. As far as readers of the articles were concerned, they could access simply the articles that they required. Their home institutions need not subscribe to a whole journal. Long-term (expensive) storage of little-used items in university libraries would also be avoided. Individuals could gain access from the library, from the home or office, twenty four hours a day.

These aspects were summarized in a report (Towards a new paradigm, 1995):

'The current paper-based system of scholarly communication, in which libraries acquire resources just in case scholars and students need them, is increasingly difficult for universities and their libraries to support and sustain. The new system should be premised on the principle of just in time services ... At present, the scholarly communication system, which remains largely paper-based, prevents universities from exercising control over the very academic information that is generated in large part within their walls. Control of academic publishing lies in the hands of a relatively small number of major publishers whose pricing practices are forcing more and more university libraries to cancel subscriptions to their journals, thus driving up unit costs for the remaining subscribers ... The content is generated almost totally by academics with the cost borne totally by creators, institutions and organisations and by various granting agencies and foundations. Commercial publishers of scholarly journals normally requires the surrender of the scholar's total copyright interest in an article as a condition of publication. Quality is controlled largely by voluntary editorial panels and by readers who assess and rank submissions. This peer review process is viewed as the single most important element in establishing the 
value of a journal and is usually an outright gift to the publisher from the scholarly community'.

Another advantage for authors and readers alike would be the ability to use the extraordinary and novel capabilities of hypertext and hypermedia. Articles could be linked online to their references; audio and video clips could be inserted to highlight certain points (and enhance the learning process for students); citations by other authors could also be monitored.

Characteristics of this new model are described as:

'A paradigm for scholarly communication in the Internet Age would:

- restore scholar centricity and be controlled by scholars and their institutions;

- be network-based;

- be unlimited in its capacity and able to support all formats;

- protect the copyright interests of both scholars and institutions;

- be responsive to the values of peer review;

- base prices on the actual direct costs to the providers, and be predictable in costs both to authors and subscribers;

- be timely;

- provide the tools to create, convert, and organise the information available through it' (Towards a new paradigm, 1995).

\section{Changes in access}

Universities - including academics and $\mathrm{AR}$ information workers - must also take into account what can be called the New Traditional Student. The profile of this student typifies older students, frequently female, often from a Non-English Speaking Background (NESB), who are juggling work, families and study. Hardaway and Brewer (1995) explain the immediate demands that are placed on universities as they face this challenge in competition with new competitors in the education sector, and new demands from business:

'Partnership with industry means that universities must be more receptive to non-traditional schedules and delivery systems. That is not to say that universities should rush to become virtual institutions that serve only as delivery systems but rather that a university which chooses only to conduct classes for a very restricted audience (students aged 18-22) in a conventional manner that preclude alternative delivery systems will not win the confidence of a business (or others!) world which is coming to understand the importance of life-long learning using a full spectrum of possible delivery systems. By refusing to make their programs and courses available at night, on weekends, and through technologyenhanced distance education programs, universities will ultimately lose control of the credentialling process, as businesses turn to provide technical training opportunities that are more consumer-oriented' (author's emphasis).
December (1994) asks, 'can a society justify creating an elite information infrastructure, one that enriches only the privileged with the resources, skills, and knowledge to use it?' A similar sentiment is expressed by Balka (1993):

'A great deal of the writing about computer networking begins with a declaration that computer networks are a democratising technology. More recent work however suggests that the inaccessibility of computer technology in general and computer networking technology in particular prohibits women's organisations from realising the potential benefits associated with computer networking'.

Despite of all its pretensions of equality and democracy, the majority of the world's population are still excluded from the Internet - the poor, the illiterate, the Third World (particularly in Africa), and women. Cynically, this is a standard litany. In a postmodernist context, these are the people who are engaged in marginalized discourses - marginalized by the grand narrative - which in this case is one of a male, computerscience-dominated culture, from which these groups have been, and by and large continue to be, excluded.

These students need to be accommodated - and ironically, this has become more of a possibility using the Internet. The Internet comprises a new type of medium, with characteristics different from the media with which we are familiar. The type of communication which it represents is known as ComputerMediated-Communication (CMC). The complexity of ways of communication on the Internet in turn leads to the creation of a number of identifiable communities. No longer is there one grand narrative or even major discourse which is the most authoritative in a discipline: the opportunity exists for a range of minor discourses to be heard. These typically represent groups which are marginalized by grand narratives. From the community of Internet users, however, an identifiable culture has emerged: Hubbard (1994), using the pseudonym Doctress Neutopia, describes it as follows (1994):

'A first glance, into Cyberspace is like entering a new frontier. The blank screen is like the vacuum of Outerspace or in the beginning there was nothingness and then came the Word. The best way I can describe this space is to say that it is our collective unconsciousness becoming consciousness as we search for meaning, striving to understand the reason or our existence and the Cosmic Order of Life. I have heard it called the Underworld and the Afterlife. Cyberspace is the place of the All-Knowing I/Eye, a place which records our written thoughts and actions'.

More pragmatically, the option of Flexible Delivery is one which is inclusive of the New Traditional Student. It can be used from a variety of points and at any time of day. The challenge for academics and AR information workers alike is to provide suitable materials in appropriate formats. The question of access to appropriate machinery needs also to be addressed by groups of professionals. 
We have at our fingertips a technology which provides a medium for communication unlike any that we have experienced before. It is challenging our notions of communication and dissemination of information, our ideas of what students should know and how they could learn. It has provided a totally different economic model to any previous similar technology, such as online database facilities. It replaces and possibly even improves on more mundane technologies such as the telephone. The Net provides the possiblity to create new communities and new societies within its metaphorical constructs, which can assist us in our real-life functioning. It demands conversation between all sectors of the information industry - and clearly between academics and AR information workers, who will need to collaborate even more closely to achieve their mutual aims. Some things we must remember are:

- New applications of information technology can be used either to increase the isolation of individuals and further fragment our society or to support new forms of collaborative work and sustain more effective communities;

- Newer media do not replace older ones - it is a case, in my view, of as well as, not instead of;

- Technical challenges are more easily resolved than social challenges; and

- The Internet is a process, not a final solution.

I am continually in awe of these maxims, which have a tenuous South African link. In a recent paper, Gilbert (1996) notes that Gandhi described these blunders of the world which lead to violence. Six weeks before he died, he discussed them with his grandson Arun Gandhi, who added one of his own. Let us avoid these blunders:

- Wealth without work

- Pleasure without conscience

- Knowledge without character

- Commerce without morality

- Science without humanity

- Worship without sacrifice

- Politics without principle

- Rights without responsibilities - Arun Gandhi

Gilbert (1996) adds four additional 'blunders':

- Technology without direction

- Connection without community

- Teaching without joy

- Learning without hope

and concludes: 'Our challenge is to use information technology to improve education and shape a future that avoids these blunders'.

\section{Bibliography}

AULICH, Sen. T G (Chair). 1990. Priorities for reform in higher education. Report of the Senate Standing Committee on Employment, education and training. AGPS: Canberra.

BALKA, E. 1993. Women's access to online discussion about feminism. Electronic journal of communication, 3(1). [Online] http://cios.llc.rpi.edu/www/ejc/v3nl193.htm.

BASS, R. 1995. Prospectus for an AAHE teaching, learning and technology Roundtable task group on faculty use of technology: understanding roles and evaluation. [Online] http://www2. ido.gmu.edu/AAHE/Technology/Future.html.

CHANDLER, D. 1995. Technical determinism or media determinism? [Online] http://www.aber.ac.uk/ dgc/tdet01.html.

DECEMBER, J. 1994. Challenges for a webbed society. Computermediated communication magazine, 1(8), [Online] http://www. rpi.edu/ decemj/works/wwwu.html.

GILBERT, S.W. 1996. Gandhi's 'Seven blunders of the World' that lead to violence ... plus 5. The labyrinth, 4(1). [Online] http:// hakatai.mcli.dist.maricopa.edu/labyforum/Win96/win96L9.html.

GOAD, T. 1995. Information literacy: the essential skills for lifelong learning and workplace success. National University Research Institute Lifelong learning conference. [Online] http//www2.nu. edu:/ nuri/llconf/conf1995/goad.html.

HARDAWAY, E. \& BREWER, P.B. 1995. Workplace literacy in the twenty-first century: the politics, the paradox and the promise. National University Research Institute Lifelong learning conference. [Online] http://www2.nu.edu/ nuri/lconf/conf1995/ hardaway.html.

HUBBARD, L. 1994. Gaia, the planetary religion: the sacred marriage of art and science: a dissertation presented by Doctress Neutopia. Amherst: University of Massacvhusetts. [Online] http:/ /genesis.tiac.net/neutopia/Gaia-Religion.html.

LANGENBERG, D.N. 1994. Information technology and the university: integration strategies for the 21 st century. Journal of the American Society for Information Science, 45(5):323-325.

MOSELEY, J. 1995. Managing and leading the university of the $21 \mathrm{st}$ century: megatrends and strategies: a report from the National Association of State Universities and Land-Grant Colleges (NASULGC) Council on Academic Affairs 1995 summer meeting. [Online] http://darkwing.uoregon.edu/ acadaff/facultystaff/ megatrends.html.

SEMPSEY, James. 1994. The psycho-social aspects of multi-user dimensions in cyberspace: a review of the literature. [Online] http://www.texas.com/ jamesiii/mud.htm.

TOWARDS A NEW PARADIGM FOR SCHOLARLY COMMUNICATION: discussion paper prepared by the AUCC-CARL/ ABRC Task Force on Academic libraries and scholarly communication. September 1995. [Online] http:// www.lib.uwaterloo.ca/documents/scholarly(aucc-carl).htm.

WAJCMAN, J. 1991. Feminism confronts technology. Sydney: Allen \& Unwin. 